\title{
Deutsch-Chinesisches Symposium „Theranostics of Prostate Cancer“
}

Das erste deutsch-chinesische Symposium „Theranostics for Prostate Cancer" hat vom 1. bis zum 3. Juni 2019 in Nanjing, China stattgefunden.

Organisiert wurde das Treffen auf deutscher Seite von Herrn PD Dr. Ali Afshar-Oromieh (Nuklearmedizin Uniklinik Heidelberg und Bern) und Herrn PD Dr. Kuangyu Shi (Nuklearmedizin TU München und Uniklinik Bern) sowie von chinesischer Seite von Herrn Prof. Dr. Hongqian Guo und Herrn Prof. Dr. Xiaozhi Zhao (Urologie des Drum-TowerHospitals Nanjing).

Für die Vorträge konnten weltweit führende Wissenschaftler gewonnen werden, 12 auf deutscher und 13 auf chinesischer Seite. Sie stellten Themen aus der Urologie, der Nuklearmedizinischen Diagnostik und Therapie, der Radiopharmazie, der Dosimetrie, Artificial Intelligence und Radiomics vor.

Das Symposium war hervorragend besucht und von unseren chinesischen Kollegen exzellent organisiert worden. Die Gastfreundschaft war überwältigend, wobei Stadtführungen in Nanjing und ein Ausflug zur historischen Wasserstadt Wuzhen die Highlights darstellten.

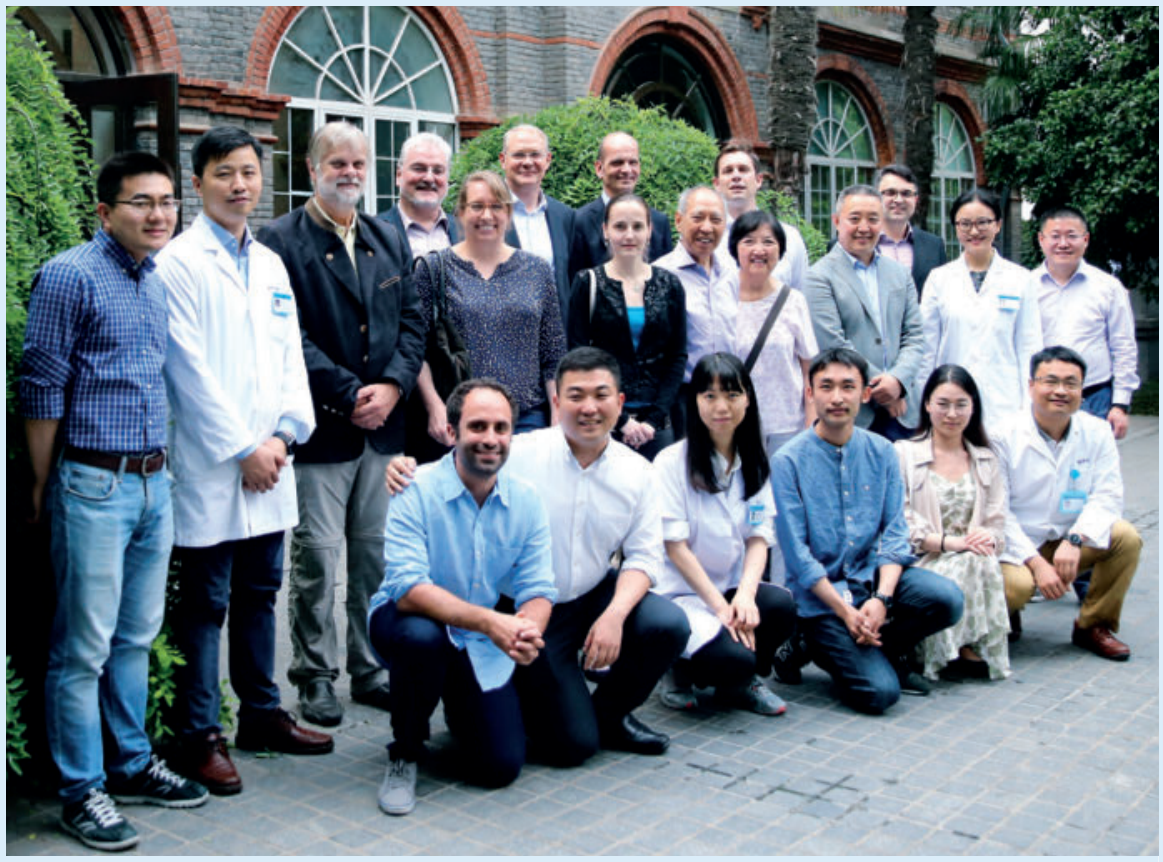

Beim Besuch historischer Räume des Drum-Tower-Hospitals in Nanjing. Die Delegation auf deutscher Seite bestand aus (obere Reihe von links nach rechts): Prof. Dr. Michael Lassmann (Würzburg), Prof. Dr. Richard Baum (Bad Berka), Prof. Dr. Hans-Jürgen Wester (TU München), Prof. Dr. Bernd Joachim Krause (Rostock), Prof. Dr. Axel Rominger (Bern) und PD Dr. Ali AfsharOromieh. Mittlere Reihe: Dr. Isabel Rauscher (TU München), Dr. Martina Benesova (DKFZ Heidelberg) und PD Dr. Kuangyu Shi (ganz rechts, TU München/Bern). Untere Reihe links: Dr. Constantinos Zamboglou (Freiburg). Die Hauptorganisatoren auf chinesischer Seite waren Prof. Dr. Hongqian Guo (mittlere Reihe dritter von rechts) sowie Prof. Dr. Xiaozhi Zhao (sitzend, zweiter von links). Nicht auf dem Foto abgebildet sind Prof. Dr. Matthias Eiber (TU München) sowie Dr. Silvan Boxler (Urologie Uniklinik Bern).

PD Dr. Ali Afshar-Oromieh 